\title{
LEPTOSPIROSE BOVINA: UMA ZOONOSE EMERGENTE
}

\author{
João Pedro Grassi de Araujo; ; Suélen Dalegrave²; Maurício Orlando Wilmsen³. \\ ${ }_{1}$ Residência em Clínica, Cirurgia e Reprodução de Animais de Produção, Pontifícia Universidade \\ Católica do Paraná - PUCPR campus Toledo, Paraná. \\ ${ }_{2}$ Residência em Clínica e Cirurgia de Pequenos Animais, Pontifícia Universidade Católica do \\ Paraná - PUCPR campus Toledo, Paraná. \\ ${ }_{3}$ Doutor, Professor do eixo de Medicina Veterinária Preventiva do Curso de Medicina Veterinária, \\ Pontifícia Universidade Católica do Paraná - PUCPR campus Toledo, Paraná.
}

DOI: $10.47094 /$ ICONRES.2021/8

\begin{abstract}
RESUMO
A leptospirose é uma zoonose emergente transmitida principalmente pela urina dos ratos e altamente prevalente em ambientes urbanos e rurais, com altos índices de prevalência em rebanhos bovinos do Brasil. A enfermidade causa diversos prejuízos de caráter clínico ao animal e/ou pessoas, além de comprometer seu eixo produtivo (carne, leite e derivados). Na disseminação estão envolvidas três espécies de roedores Rattus norvegicus, Rattus rattus e Mus musculus principalmente em áreas urbanas e em áreas rurais, o próprio bovino possui o papel de vetor. Levando em consideração que a Leptospirose é uma doença que se apresenta em diferentes formas, além da fase clínica, ao realizar testes sorológicos de manutenção no rebanho, os mesmos indicam a soroprevalência do agente, aumentando a incidência de abortos, fetos mumificados e nascimento de bezerros fracos. A imunoprofilaxia consiste na principal ferramenta de controle do rebanho, além do controle ao acesso de outros vetores em bebedouros e comedouros.
\end{abstract}

PALAVRAS-CHAVES: Doenças infectocontagiosas; Bovinocultura; Sorovar.

ÁREA TEMÁTICA: Medicina veterinária

\section{INTRODUÇÃO}

Há uma importância relevante em compreender que animais considerados reservatórios aumentam o risco de infecção e, além disso, diferentes espécies podem ser suscetíveis à diferentes cepas da bactéria, devido a alguma forma de coadaptação ao longo do tempo. Desta forma, é importante entender que os riscos em que o profissional da medicina veterinária está submetido é 
alto em decorrência de suas atividades serem executadas com diferentes espécies animais. Assim, a presença de diferentes sorovares contaminando diferentes espécies: cães (L. Canícola), bovinos ( $L$. Hardjo e L. Tarassovi) e suínos (L. Bratislava e L. Icterohaemorragiae) aumentam a incidência da doença nesses profissionais.

Muito embora os ratos sejam considerados os principais reservatórios, sobretudo, o Rattus norvegicus, por abrigar o serogrupos de Leptospira Icterohaemorrhagiae, considerado o mais patogênico para espécie humana, outras espécies podem servir de reservatório de outros sorovares. De acordo com dados do IBGE (2019), o Brasil conta com mais de 214 milhões de bovinos, destinados a produção de carne e leite, esses número disparam incertezas a respeito da veiculação da doenças de caráter zoonótico dentro da cadeia produtiva da bovinocultura. As leptospiroses constitui um grupo de destaque na veiculação e difusão desses patógenos em todo mundo. (LOUREIRO; LILENBAUM, 2019).

No Brasil, a distribuição dos sorovares em destaque para espécie bovina são restritos a Hardjo (genótipo hardjoprajitno), Pomona, Icterohaemorrhagiae, Wolffi, Goiano e Guaicurus. Contudo, as bactérias do gênero Leptospira, estão subdivididas em em três categorias com mais de 250 sorovares (PETRAKOVSKY et al., 2014). O objetivo desse trabalho foi monitorar a presença do agente em um rebanho bovino de um hospital escola da Clivet, fazenda escola da Puc-PR, localizada na cidade de Toledo, região Oeste do Paraná.

\section{METODOLOGIA}

Foi realizado através de um inquérito sorológico no rabanho bovino da PUCPR - campus Toledo, a presença de sorovares com caráter zoonótico relacionados as Bactérias do gênero Leptospira em 21 vacas de corte. Antes e depois dos animais serem imunizados A coleta de sangue foi realizada em dois momentos, pré (6 animais) e pós vacinação (15 animais), diretamente da veia caudal. O sangue foi armazenado em tubos sem anticoagulante previamente identificados. Após a obtenção das amostras, as mesmas foram enviadas ao laboratório clínico, onde foram centrifugas e alocadas em tubos ependorfe e sequencialmente congeladas a temperatura de $-20^{\circ} \mathrm{C}$ até o momento do processamento. $\mathrm{O}$ porcessamento das amostras foi realizado em laboratório particular, através do teste de aglutinação modificado ou ensaio de microaglutinação (MAT).

\section{RESULTADOS E DISCUSSÕES}

A partir dos resultados dos exames sorológicos foi possível entender a distribuição de diferentes soravares no rebanho de fêmeas bovinas. Do ponto de vista de veiculação de sorovares infecciosos que compartilham infecções entre humanos e animais, apenas um animal foi sorologicamente identificado com o sorovar L. Icterohaemorraghie (1:400), indicando inclusive infecção ativa pelo agente. O manejo determinado para esse animal envolve critérios de acompanhamento clínico, sorológico ou 
ainda qualquer impacto reprodutivo. A fêmea contaminada com este sorovar teve a prenhez confirmada sem abortamento ou mumificação, contudo, o bezerro nascido apresentou-se menor que o esperado.

Os resultados sorológicos dos animais no momento pré imunização, reveleram a presenca de L. Wolffi e L. Pomona com título de 1:100 em um animal e no segundo animal apenas L. Wolff 1:1800. De acordo com o manual de testes diagnósticos de animais terrestres da OIE de 2013, animais não vacinados, com titulação $\geq 100$, sugerem contato com o agente infeccioso e animais com titulação $\geq 400$ está relacionado com infecção ativa. De acordo com Petrakovsky et al., (2014), o teste de microaglutinação (MAT) de eleição para vários ensaios sorológicos para diagnosticar a leptospirose na América Latina, tendo como maior resultado de sorovares a L. Hardjo, Wolffi e Tarassovi. Segundo Zaratonelli et al., (2018), o MAT foi utilziado para detecção de rebanhos infectados no Uruguai, utilizando a titulação de $\geq 200$, sugerindo infecção ativa, para novas amostras e exames de PCR. No segundo momento, com os animais já vacinados, foi considerado titulação $\geq 400$ para confirmar a infecção ativa.

Dos 15 animais, 5 apresentaram titulação $\geq 400$ para L. Bratislava, Icterohaemorraghie, Pomona, Wolffi e Hardjo. Os animais com alguma titulação somaram 46,7\% de amostras positivas. Segundo Benschop et al., (2021), apontaram em um inquérito sorológico de um rebanho que esses sorovares apresentam alta prevalência em rebanhos bovinos. O teste de microaglutinação se mostra um excelente teste para avaliação de rebanhos, porém, quando a avaliação de animais com características crônicas da infecção e eliminação do agente pela urina, seria o emprego do teste de reação em cadeia pela polimerase (PCR), e a resposta para tal avaliação se dá pelo uso inadequado da técnica sugerindo resultados falsos negativos (LIBONATI et al., 2017); (LOUREIRO; LILENBAUM, 2019).

Após a confrimação do diagnóstico sorológico no rebanho, uma fêmea apresentou mumificação fetal sendo o título 1:1800 do sorovar L. Wolffi. Mumificações fetais podem ocorrer por diversos fatores, entre eles a Leptospirose (BRAGA et al., 2014). A leptospirose causa diversos distúrbios reprodutivos, como mumificação, infertilidade além de abortos no rebanho (MORI et al., 2017).

\section{CONCLUSÃO}

Este levantamento sorológico permitiu concluir que diferentes sorovares de Leptospiras spp são edêmicos no rebanho da instituição. Assim, através do monitoramento soroepiodemiológicos novas estratégias de para o controle o profilaxia do rebanho foram adotadas, principalmente quanto ao animal identificado com o sorovar L. Icterohaemorraghie, também reconhecido infectar seres humanos. A fêmea positiva não apresentou nenhum tipo de transtorno reprodutivo, e o controle da infecção foi realizado através do acompanhamento clínico e da imunização do animal.

\section{REFERÊNCIAS}

BENSCHOP, Jackie; NISA, Shahista; SPENCER, Simon E. F.. Still 'dairy farm fever'? A Bayesian 
model for leptospirosis notification data in New Zealand. Journal Of The Royal Society Interface, [S.L.], v. 18, n. 175, p. 20200964-20200964, fev. 2021.

BRAGA, P.O. e BARROSO, R.M. Aspectos fisiopatológicos da mumificação fetal. PUBVET, Londrina, V. 8, N. 15, Ed. 264, Art. 1752, Agosto, 2014.

IBGE- INSTITUTO BRASILEIRO DE GEOGRAFIA E ESTATÍSTICA. Efetivo de rebanho, por tipo (cabeças), Rio de Janeiro: IBGE, 2019. Disponível em: https://www.ibge.gov.br/estatisticas/ economicas/agricultura-e-pecuaria/9107-producao-da-pecuaria-municipal.html?=\&t=destaques. Acessado em: 12 de março de 2021.

LIBONATI, Hugo; PINTO, Priscila S.; LILENBAUM, Walter. Seronegativity of bovines face to their own recovered leptospiral isolates. Microbial Pathogenesis, [S.L.], v. 108, p. 101-103, jul. 2017.

LOUREIRO, Ana P.; LILENBAUM, Walter. Genital bovine leptospirosis: a new look for an old disease. Theriogenology, [S.L.], v. 141, p. 41-47, jan. 2020.

MORI, Marcella; BAKINAHE, Raïssa; VANNOORENBERGHE, Philippe; MARIS, Jo; JONG, Ellen de; TIGNON, Marylène; MARIN, Martine; DESQUEPER, Damien; FRETIN, David; BEHAEGHEL, Isabelle. Reproductive Disorders and Leptospirosis: a case study in a mixed-species farm (cattle and swine). Veterinary Sciences, [S.L.], v. 4, n. 4, p. 64, 1 dez. 2017.

OLIVEIRA, Stefan Vilges de; ARSKY, Maria de Lourdes Nobre Simões; CALDAS, Eduardo Pacheco de. RESERVATÓRIOS ANIMAIS DA LEPTOSPIROSE: uma revisão bibliográfica. Saúde (Santa Maria), [S.L.], v. 39, n. 1, p. 9-19, 1 mar. 2013.

PETRAKOVSKY, Jessica; BIANCHI, Alejandra; FISUN, Helen; NÁJERA-AGUILAR, Patricia; PEREIRA, Martha. Animal Leptospirosis in Latin America and the Caribbean Countries: reported outbreaks and literature review (2002-2014). International Journal Of Environmental Research And Public Health, [S.L.], v. 11, n. 10, p. 10770-10789, 16 out. 2014. 